Chapman University

Chapman University Digital Commons

Education Faculty Articles and Research

College of Educational Studies

5-31-2016

\title{
Design, Participation, and Social Change: What Design in Grassroots Spaces Can Teach Learning Scientists
}

Miguel Zavala

ChapmanUniversity,mzavala@chapman.edu

Follow this and additional works at: http://digitalcommons.chapman.edu/education_articles

Part of the Bilingual, Multilingual, and Multicultural Education Commons, and the Curriculum and Instruction Commons

\section{Recommended Citation}

Zavala, M. (2016). Design, participation, and social change: What design in grassroots spaces can teach learning scientists. Cognition e Instruction, 34(3): 236-249. doi: 10.1080/07370008.2016.1169818

This Article is brought to you for free and open access by the College of Educational Studies at Chapman University Digital Commons. It has been accepted for inclusion in Education Faculty Articles and Research by an authorized administrator of Chapman University Digital Commons. For more

information, please contact laughtin@chapman.edu. 


\section{Design, Participation, and Social Change: What Design in Grassroots Spaces Can Teach Learning Scientists}

\section{Comments}

This is an Accepted Manuscript of an article published in Cognition \& Instruction, volume 34, issue 3, in 2016, available online: http://dx.doi.org/10.1080/07370008.2016.1169818. It may differ slightly from the final version of record.

\section{Copyright}

Taylor \& Francis 
Design, Participation, and Social Change: What Design in Grassroots Spaces Can Teach

Learning Scientists

Miguel Zavala

Chapman University

Correspondence should be addressed to Dr. Miguel Zavala, College of Educational Studies, Chapman University, Reeves Hall 217, One University Drive, Orange, CA 92866; mzavala@chapman.edu; 714-516-5965. 


\begin{abstract}
While a science of design (and theory of learning) is certainly useful in design-based research, a participatory design research (PDR) framework presents an opening for learning scientists to rethink design and learning as processes. Grounded in the autoethnographic investigation of a grassroots organization's design of a local campaign, the author traces the successive transformations of design artifacts, delineating a narrative character to design within grassroots spaces. One major lesson is that centering the question of participation is not just about including historically marginalized peoples at the core of design; it has the potential to “desettle" projects at a fundamental level, challenging dominant epistemologies that inform the practices of learning scientists, and thus transforming the field in ways that have yet to be systematically explored. More broadly, this study highlights the need for future research on design practices as they take form within understudied spaces, such as grassroots organizations.
\end{abstract}


Design, Participation, and Social Change: What Design in Grassroots Spaces Can Teach Learning Scientists

The recent integration of iPads in classrooms by the Los Angeles Unified School District (LAUSD), representing the biggest purchase totaling $\$ 1.3$ billion for any public school district, illustrates the tension and struggle over technology and participation in design. While Superintended Deasy publicly announced the educational value of iPads for every student as a civil rights issue and local activists question what they argue is the neoliberal, corporate agenda behind their dissemination, it took several hundred students in an urban district of over 750,000 to stall the iPad rollout (Blume, 2013). Perhaps not anticipating that students would bypass district administrative settings and use the iPads for their own purposes, this experiment highlighted tensions that emerge when one considers participation in the context of learning and design: situated in a nexus of power relations, technologies and their design are not neutral processes. Thus, from a participatory design research (PDR) framework we might ask: What happens when participation stretches beyond collaboration between researchers and the immediate learning community of teacher, students, and others directly involved? How does increased participation allow for the expansion and shifts in the objects of design activity? When the participants themselves become integral to the development of education projects, I argue that even the very practice of design is transformed. Design, with its qualities of systematic inquiry manifested in testing of educational tools and technologies across iterative cycles, etc., is historically shaped by both the communities that undertakes design projects and the practices that orient the activity. Increased participation has the potential for breathing new life into design 
projects, by drawing upon visions of possible worlds rooted in distinct and marginal epistemological frameworks.

My autoethnographic investigation of campaign design within a grassroots teacher organization highlights this process: the dialectic between community and orienting practices and how these in turn shape design activity. I define orienting practices broadly as the spaces and practices of design, including the values that make up such spaces and practices. In this study I focus on the design of the Save South LA Elementary campaign undertaken within the Action Research Committee (ARC) of the Association of Raza Educators' Los Angeles Chapter (ARELA), a teacher-led grassroots organization. The Save South LA Elementary campaign was an 8month local campaign to save South LA Elementary from being taken over by charter management organization or other outside agencies, as some teachers and the local teachers' union framed the issue. Drawing on the extant research on design practices, I outline in the next section four key ideas that serve as a broader conceptual framework for analyzing participation and its transformation of design practices. In particular, I build on these ideas to develop an emergent, grounded theory of design that enables us to understand the qualitative shifts in participation and the expansion of the object of the Save South LA Elementary campaign.

\section{Conceptual Framework}

\section{Centering Participation in Design}

Questions of participation, more recently introduced by Indigenous and other scholars in the learning sciences (Bang, Medin, Washinawatok, \& Chapman, 2010; DiSalvo, Clement, \& Pipek, 2013; DiSalvo \& DiSalvo, 2014; Medin \& Bang, 2014), have been debated in other fields for some time, in particular participatory action research (PAR) in Latin America (see FalsBorda, 1970; 2006). Lessons learned in PAR over the struggle to democratize knowledge, where 
historically marginalized communities reclaim research for themselves, are useful in helping us think through what increased participation might mean for the learning sciences. One major lesson is that centering the question of participation is not just about including historically marginalized peoples at the core of planning or design. It has the potential to "desettle" (Bang, Warren, Rosebery, \& Medin, 2012) projects at a fundamental level, challenging dominant epistemologies that inform the practices of learning scientists, and thus transforming the field in ways that have yet to be systematically explored.

Nevertheless, design-based researchers, in their critique of controlled experiments, have sought to address methodological problems via situated, collaborative forms of design. "We should engage stakeholders and implementation facilitators as collaborators whose potential actions can become part of the design in situ" (Barab, 2014, p. 161). Barab's reframing of design-based research opens the possibility for situated forms of collaborative design (Penuel, Fishman, Cheng, \& Sabelli, 2011), where “practitioners have greater ownership over the [design] process," (Svihla, 2014, p. 36). However, some scholars have been critical of design-based research and its tendency to re-center the researcher and her or his role in design. As Engeström (2011) points out, "Scholars do not usually ask: Who does the design and why?" (p. 3). The dominant paradigm is one that places design in the hands of learning scientists (who often work in tandem with institutional bureaucracies and large funding agencies).

An emerging field, PDR involves distinct, yet related, methodologies such as formative intervention research (Engeström, 2011), social design experiments (Gutiérrez \& Vossoughi, 2010), and community-based design (CBD; Bang et al., 2010), among others. One strand of PDR that radically transforms participation is the CBD model, which involves "the comprehensive participation of community members, including teachers, elders, parents, community experts, 
researchers, and youth in all aspects of the research" (Bang et al., 2010, p. 4). This model is distinct from the human research laboratories (see Engeström \& Sannino, 2010) in one fundamental way: CBD projects grow out of grassroots spaces and are organic to historically marginalized communities rather than to institutional places of work or school. DiSalvo and DiSalvo (2014) comment that CBD represents a "bridge" between PAR and PDR, yet because it is so new its potential as a methodology and framework has "yet to be developed in the learning sciences" (p. 794). I see my own research as being in dialogue with PDR and the CBD model. My initial investigation of design in a grassroots organization's campaign, which I delineate below, highlights the potential for grassroots spaces to shift and transform power dynamics not just among individuals but also between university and communities. My findings shed light on and problematize the importing of design processes on the part of "experts" and the related assumption that endogenous design processes are not already taking place.

\section{Design Models as Situated, Cultural Activity}

Because design thinking is situated, culturally specific activity, the models and metaphors that have come to be normalized as an expression of autonomous, rational activity by some scholars and practitioners, are challenged by communities that introduce diverse ways of conceptualizing design. Razzouk \& Shute's (2012) review of the extant literature on design highlights the predominance of individualistic models of design thinking where design is something designers do; the exploration or conceptualization of design as social activity is rarely pursued. Even in situations where people work in design teams, their understanding of design thinking gravitates to what is inside the head, that is, the cognitive processes, of individual designers. While Razzouk and Shute's (2012) design thinking competency model may be useful in outlining the cognitive maps and schemas of designers, design thinking components are 
posited as decontextualized skills that may be used in teaching novices how to become better designers. In contrast to this individualistic model of design, Cole (2007) offers a shared and distributed model of design, manifest in researchers expanding their roles as they become coparticipants in the process of learning within classroom settings they investigate. Their intervention illustrates, as he argues, "designing effective lessons through in situ modifications of pre-existing designs" (p. 78).

As academic researchers interested in learning, our tendency is to resort to models of design practice in fields considered exemplars of it, that is, STEM. While important lessons can be drawn from the design models of engineers, software programmers, among other professions that make use of "design rationales" (Moran \& Carroll, 1996), a major problem persists when we seek to export design practices to learning within concrete educational spaces: The design environments engineers and software programmers conceive are qualitatively different from the social, dynamic, and changing nature of learning in classrooms and informal settings. Yet, what does design look like and how does it mediate praxis in other communities, say among sculptors, musicians, and community organizers? This question is not one of the practical uses of models but rather a question that points to one of the larger arguments in this paper: how participation can desettle what have become normative design processes, such as the metaphors and models used by learning scientists.

\section{Why Learning Contexts Won't Hold Still for Researchers}

PDR is a methodology that can also desettle researchers' own metaphors and models of learning contexts. Attuning to design as situated cultural activity necessitates a particular repositioning of our understanding of design practices, grounding them in endogenous models already present in the spaces of learning we investigate. While challenging the discourse of 
controlled experiments, design-based researchers, though theorizing learning as a complex, iterative process, design "learning environments" with "notions of perfection, completeness and finality" (Engeström, 2011, p. 3), thus minimizing contradictions in design development, implementation, etc. as well as the agency of participants. "In contrast to linear and top-down notions of design experiments, social design experiments are open systems that are subject to revision, disruption, and contradictions" (Gutiérrez \& Vossoughi, 2010). Scalability and sustainability have been identified as core problems by design-based researchers (Penuel et al., 2011; Svihla, 2014). I contend that at the root of these problems is the fact that learning will not hold still for researchers' ideational and rational models: environments are historically shaped, socially constructed, and in constant motion. Engeström (2009) argues that the conceptualization of learning environment in the extant literature tends to be static and hierarchical. From a design approach, such models are improved via feedback loops, yet this process lacks embeddedness:

This task domain and technology are designed and implemented in isolation from (a) the institutional logic of the activity of the school or other organization in which they are located and (b) the logics of the life and study activities of the learners. (p. 22)

Engeström (2009) argues for a situated approach to design, where formative interventions take place in context of its users within a given activity system or systems:

If one takes the activity systems of the users (for example, teachers and students) as the starting point, implementation no more appears as a task of implanting an alien bubble in an unknown territory. Instead, the issue is reframed as one of transformation. (p. 25) Likewise, design should emerge as reflexive activity that is robust yet situated in the conditions of learning. Drawing upon a sociocultural understanding of learning contexts as complex interacting systems, the historical lens enables researchers to understand how learning 
environments grow out of an amalgam of social forces that perpetuate inequity. Education contexts, especially public school settings, are often conflicting practices wrought with power and human agency (Booker, Vossoughi, \& Hooper, 2014; Lee, 2013; Nasir, Roseberry, Warren, \& Lee, 2014). Rather than discouraging researchers, the historical development of educational contexts signals hope for a design-based research that is formative (Engeström, 2011) and participatory (Bang et al., 2010; Gutiérrez \& Vossoughi, 2010), co-constructed by researchers immersed in particular spaces and practices along with the people integral to learning, whether teacher, students, parents, and historically marginalized communities more generally.

\section{Expansive Learning and Boundary Objects}

Building on the tradition of cultural historical activity theory, two orienting concepts that are useful in understanding the situated, culturally specific ways in which design practices are mediated in the campaign design of Save South LA Elementary are expansive learning and boundary objects. The theory of expansive learning defines learning as "involved in constructing and implementing a radically new, wider and more complex object and concept for their activity" (Engeström \& Sannino, 2010). At the core of this redefinition of learning is the metaphor of expansion. While learning is a social practice, the creation of historically new concepts emerges out of peoples' agency and their capacity to envision (and bring to life) possible worlds. The notion of the "expansion of the object" is an agentive, practice-based model of learning: people engaged in particular social practices — composed of complex, interacting activity systems - have the capacity to reflect upon the object, to take a distance from their current situation, and thus open possibilities for transforming their reality. Although contradictions inherent to a particular situation may generate change, Engeström (2011) argues that a particular kind of agency that is both deliberate and reflexive pushes learning and 
development forward: "the human potential for agency, for intentional collective and individual actions aimed at transforming the activity," (p. 610). At the heart of this kind of reflection is the formation of concepts, which are "embodied, embedded and distributed in human activity systems" (p. 611). I liken concepts to future-oriented cartographic maps that both represent the geological and historical layering of activity systems but also are tools for transforming their contours and landscapes. A marked quality of concepts is that they are partial (to participants), ambiguous, collective (as interobjects) yet individual, and visions of possible worlds (Engeström, 2011, p. 611). Engeström (2011) explains:

The formation of complex concepts is not just internalization of culturally given concepts but above all externalization, generation of culturally new concepts (which also need to be internalized in use). Expansive learning leads to the formation of a new, expanded object and pattern of activity oriented to the object. (p. 612)

The boundary object concept is useful in understanding concept formation within a given activity system. Akkerman and Bakker (2011) have developed a working model that accounts for learning "at the boundary" or that occurs in situations characteristic of all cultural activities, which are complex and embedded in multiple interacting activity systems. The design of the Save South LA Elementary campaign, the focal setting analyzed in this paper, occurs at the interstices of overlapping activity systems within an organization (i.e., ARE), simultaneously intersecting with other activity systems, the most prominent ones being the object of schooling in large urban school district bureaucracies and the visions and aspirations of the families in a given school community. The campaign design within the ARC, as I will unpack, works at multiple levels, simultaneously. Thus, the expansion of the object is both a collective achievement and struggle. It is not derived vis-à-vis rational reflexive processes, such as testing of learning 
technologies, as documented by formative intervention researchers studying expansive learning cycles in other spaces.

Conceptualizing design as cultural activity allows us to understand the internal and external tensions that lead to its development. Design is a form of praxis. Though characterized by people thinking and modeling future action together, the design practices are themselves negotiated and emergent. It is emergent in the sense that participants concretize elements of design in the context of practical work within activity systems. In the study presented here, this was manifest as teachers engaged in designing a campaign that involved extensive actionresearch on corporate charter schools. Forging the object via expansion necessitated some form of struggle — it was not merely generated vis-à-vis latent contradictions but by the substantive inclusion of participants, here ARC teachers who were generally drawn to a progressive vision for social change. The inclusion of these teachers introduced something new, whether strategies or visions of the design objects. In the case of $\mathrm{ARC}$, there was a deliberate attempt by its participants to generate contradictions via action-research and the education of ARE members, and to see these as generative strategies in the expansion of the object that included a growing critique of corporate charter schools. This signals a direction for PDR, to prioritize how participation mediates qualitative relations amongst participants and the ideas they co-develop in design praxis.

\section{Methods}

\section{Site and Context}

By design, ARC was the space where chapter campaigns and community projects were seeded. The committee convened monthly to debrief and brainstorm on campaign efforts. The committee was composed of six members, two of which were teachers at South LA Elementary, 
two graduate students, another teacher activist, and myself. At the time, I had been in the leadership of the organization for four years and was also actively involved with a new statewide structure, the Concilio. Below (Figure 1) is an organizational chart of ARE organic structures. My participation in ARC was preceded by two years of organizing in the committee on publicity and community relations. I characterize my involvement in the organization and ARC specifically as driven by the goals of the committee primarily, with my autoethnographic research as secondary. ARC committee members were fully aware of the research I had undertaken on behalf of a university. I was an integral member of ARC and led some of the action-research and political education components of the Save South LA Elementary campaign.

Figure 1 About Here

Tracing the development of organic structures within ARE-LA Chapter (ARE-LA), ARC had undergone two major changes. First, where in the past ARC often assumed ad hoc status, with the Mesa Directiva (the chapter leadership body) directing campaign work, the committee had now been fully constituted. By fully constituted is meant that the ARC committee was fully functional as a standing rather than ad hoc committee, with a Chair presiding over meetings and having at least three active ARE-LA members. Second, given the history of past ARE campaign work and a restructuring that took place during the summer, the new Mesa in conjunction with the State Concilio (the statewide leadership body) had been pushing for more pro-active rather than reactionary campaigns. This organic history of ARE-LA is relevant and important in understanding the approach taken with respect to South LA Elementary. The school was "not on the chopping block" as Elisa, one of the committee members and teachers at the school, iterated, so this was a test to see if we could, as a chapter, design and undertake a campaign that would be 
anticipatory, strategic, and well planned. Thus, the practical design work in ARC was not just about engaging in a local campaign: It represented a deliberate expansion of the object, that is, the transformation of the organization's members from activists to community organizers. This distinction was made explicit in the organization's membership manual as one between individualistic, reactionary ("activist") versus collectivist, proactive, or anticipatory (“organizer") qualities (see Figure 2 below).

The Save South LA Elementary campaign could be characterized as having three general phases. The first phase included the political and social context that lead up to the campaign. The struggle to reclaim South LA Elementary grew in response to local, state, and national policies that had been underway, with the appointment of Arne Duncan as Secretary of Education, and with the passing of Public School Choice: A New Way at LAUSD, that set in motion the takeover of at least two-thirds of the schools in the district by charter management organizations. ${ }^{1}$ The second phase of the campaign began when the committee drafted a campaign proposal with set goals and strategies for how to accomplish those goals, thus giving the campaign a clear direction. This phase involved an education campaign as well as extensive action-research on corporate charter schools and resistance to neoliberal privatization efforts in other schools within the district. The third phase began with increased resistance to community forums at South LA Elementary. This phase encompassed our difficulty in getting the qualitative research component off the ground, in which we would bring together the narratives of teachers and students in corporate charter schools. Eventually, the campaign lost momentum, with only one research project on the agenda: the production of a documentary short on the privatization of education that would serve to educate parents on the issue.

\section{Data and Analysis}


As an integral member of the organization, I use autoethnography (Anderson, 2006; Chang, 2008) as an interpretive strategy for understanding the ways in which organic structures within the organization are constituted and in particular how ARC members conceptualized and mediated the design of a pro-active campaign. I draw upon 18 months of fieldnote observations and archival information representing key ARE organizational documents. I also conducted indepth interviews with three ARC members, midstream as the campaign was underway and postcampaign as a strategy for reflecting upon the development of the campaign and the chapter as a whole. Interview protocols were developed that asked participants to provide context for what had transpired within the committee space; interviews were also opportunities to include participants' changing conceptions about campaign goals, processes, and outcomes. All fieldnote, interview, and archival data were analyzed using qualitative coding software. Revisiting the campaign involved extensive re-reading and memo writing strategies that assisted me in charting both the ethnographic context and architecture of the campaign. I pay particular attention to the ways in which the campaign was designed. Interview data were used to both provide insights with respect to participants' decisions and to articulate their conceptualizations of design processes and goals.

\section{Findings}

\section{Participation and Design as Emergent}

The campaign and its conceptualization grew out of ARC, where the campaign proposal was drafted. Yet, prior to its crystallization, it emerged at the boundaries, where two ARC members, teachers at South LA Elementary, introduced the increased tension at their school to the ARC committee. In our initial committee meetings, these two teachers reported growing opposition to one of the choice options being offered by the district, specifically the charter 
management organization model. Nevertheless, while opposition to charter management organizations was growing, other teachers supported local design and other models, were they forced to opt for one of the choice options as mandated by district policy. Campaign design emerged as a form of spontaneous activity, a re-action to a new context created by an external district policy (see Figure 2). In this sense, Penuel's (2014) characterization of formative intervention research parallels what happens in organic spaces such as ARE: "The design process begins with a problem of practice as encountered by participants in an activity system, rather than with researchers' goals for the improvement of teaching and learning," (p. 100). While problems of practice are often about learning and pedagogy, for Tina and Elisa, both ARC members and teachers at South LA Elementary, the practical problem they encountered were, as they reported, about "limiting what I can teach." Hesitant about what they viewed as a narrowing down of the curriculum in the context of 20 years of standards based reforms in the district, my sense as a researcher of large urban districts and community organizer is that teachers like Tina and Elisa were feeling overwhelmed with so many changes with reforms from above that seemed to exclude teacher voice and input. At that point, the campaign had yet to be defined in a collective and deliberate way. This is represented in Figure 2 as Object A.

Figure 2 about here

As the object expanded, a central mediational tool was the development of a campaign protocol and model for action-research. Both artifacts grew out of a resolution of internal contradictions within the organization and represent an expansion of the object, which shifts from the noncharterization of South LA Elementary to a consideration of moving towards an alternative model to charterization (Figure 2, Object B) to the idea of teachers becoming 
community organizers (Figure 2, Object C). In my analysis of the new expanded object over time, I have come to characterize these movements as negotiated and emergent. The expansion of the object is negotiated as I illustrate below in the sense that individual voices are taken into account but there is either disagreement at points or there is collective movement forward without all committee or chapter members having the same understanding of the object. I recall how disagreement was fostered amongst the leadership and when collectivizing decisions with members of the chapter. Rarely were decisions taken as a result of a vote; collective decision via consensus was the ideal situation.

The campaign design included an integral reflexive component, when metadiscussions on the feasibility of the campaign lead to rethinking of campaign goals, a practice undertaken formally within the committee and the ARE-LA Mesa. I illustrate this metadiscussion and negotiation in the following fieldnote excerpt. After several months of reading and researching within the ARC committee, we came to some agreement about supporting the Expanded School Based Model (Figure 2, Object B), which Elisa explained was gaining support by teachers, especially "because teachers did not want to lose job security and benefits through charter conversion."

Fieldnote excerpt. Elisa begins with an overview of South LA Elementary and the developments at her school. We review the parent flier, and Mesa members make suggestions. Elisa then discusses how teachers at her school are moving for the Expanded School Based Management model.

Maria, Mesa Chair, suggests looking at LAUSD documents and know what the process is for voting for a particular option. Beatriz adds that the Expanded School Based Management model is no different than what is currently in place, namely school site councils. 
Maria asks if there are examples of the model the committee is pushing for. Maria raises questions with respect to the decision-making process within this management model. She asks what official documents and district policy statements are out there that outline this process: "How much say are teachers and parents really given?"

We then transition into the presentation of the committee statement on charter schools. I used the version dated September 22nd. I handed each Mesa member a copy and read the statement out loud. Suggestions were made and I took down notes on my paper copy of the statement. A point of clarification in statement pertained to how charters depend on standardized test scores. "All public schools rely on standardized test scores," said Maria. Maria makes a major suggestion. "The framing needs to provide an alternative, not just to the options but even to public schools as they are now." She makes it clear that she won't sign off the statement as it is now as Chapter Chair, because it explicitly supports the local School Based Management model.

I then iterate that more research is needed on this management model. I concur with excluding any explicit support for a particular model, but that we include a set of principles that we would support, such that any model could be weight according to these.

Maria says something important: "The campaign is not as urgent as we think. The LAUSD motion is framed as an indefinite policy that will affect more and more schools over time." Maria then suggests taking on South LA Elementary as a "case study" to document and learn about the organizing and process.

“There's no doubt you'll get resistance, even while trying to implement this model," adds Beatriz.

Two things were playing out here. On one level, we were negotiating and gaining further 
clarity on the object of the campaign. That is to say, we were rethinking the goals and scope of the campaign. This would require reframing of the problem of charterization as privatization and would entail an analysis of public schools as well. On another level, we were learning how to collectivize ideas as we communicated between one organic structure, that is, the ARC committee, to another, that is, the Mesa. The points that Maria and Beatriz raised not only served to enrich our on-going analysis and to think more carefully about the campaign object, they represent the negotiated and emergent character of design processes within grassroots organizations. Those of us in leadership positions were trained to push for divergent viewpoints and as long as they developed vis-à-vis organic structures (see Figure 1 above), they moved us forward in some collective way. While consensus is a goal within ARE, it is never a seamless process. Thus, the campaign design object expands as people within a given community took up its design. Yet, returning to one of my main arguments in this study, its not just about hearing different voices and running through seeming democratic processes; what matters is the quality of those discussions and how participants' voices develop in relation to the expansion of the object. I, for example, developed through my research a more nuanced understanding of what charterization meant and had to rethink my own framing of contradictory positions. Charter schools were presented as alternatives yet reinscribed many of the logics of public schools that many in ARE were opposed to, such as using standardized tests as a measure of learning, which Maria was keen on arguing in the fieldnote excerpt above.

\section{The Struggle for the Object: Boundary Crossing and Learning}

The ethnographic analysis of the Save South LA Elementary campaign object allows us to see the contraction and expansion of the object over time and how this in turn shapes design activity. Contexts are shaped by participants and bleed into each other as different activity 
systems interact and coalesce. In grassroots spaces, which may be characterized as informal due to their diminished institutional layering and as they are sustained by people themselves and less by bureaucratic rules and regulations, the object is not simply expanded vis-à-vis collective reflection and testing of models, it is struggled for at many levels. Precisely because of the political nature of grassroots campaigns, contexts and the goals tied to these are largely contested. In the previous fieldnote excerpt, the idea of moving towards an Expanded School Based Model (Figure 2, Object B) was shut down by the Mesa leadership because it was ultimately decided that it wasn't a viable alternative to existing public school governance structures. Vying for one type of school over another was informed through deliberation yet was impacted by the analysis members bring in understanding campaign issues and processes.

Furthermore, Elisa and Tina's reflections upon the challenges encountered in getting the campaign off the ground at South LA Elementary highlight the tension that exists between grassroots progressive organizations and institutional goals represented by school administrators. This is evident in Elisa's response to the question of challenges they experienced at their school: "Most of the challenges came from the principal not wanting to give us the space to actually hold these community meetings, and we kept bugging about it, and asking him for it, when he finally did he gave us that really terrible date." In my interview with the two teachers, they identified the school principal as representing "institutional" interests and "not understanding teachers and the community." Perhaps the greatest challenge involved envisioning more than the initial object of the campaign (Figure 2, Object A), voiced by some teachers as not wanting their school to be taken over by a charter management organization. Elisa highlights this tension: "And then the list comes out and it turns out we're not on the immediate chopping block... So [the campaign] kinda just fell apart, because there wasn't that immediacy, they didn't see it as a threat anymore." The 
list Elisa references is the district's list of low performing schools that would be open for internal and external entities to take over and reconstitute. Both Elisa and Tina did not agree completely with the sudden shift by South LA Elementary teachers in response to the potential threat of losing their school, which they interpreted as politically "reactionary" and signaled that teachers were "unprepared to respond to policy changes from above."

Including participants in the planning table introduces distinct objects of other robust activity systems. In this case the South LA Elementary principal had his own object and goals in mind. He coopted the process by controlling the community forum agenda and times, and disallowing ARE community surveys. Still, there is another, concomitant, process that stalled the work, namely the bureaucratic, layered, nature of program design within school districts: "Doing a whole school plan which is like over one hundred and something pages with like budgets and curriculum and schedules and pay," (fieldnote, Elisa). Finally, there is the extensional, boundary crossing nature of emergent design: the context that activates the campaign changes: "So it kinda just fell apart, because there wasn't that immediacy, they didn't see it as a threat anymore," (fieldnote, Elisa).

\section{Narrative Character of Campaign Design in ARE}

Given the contested nature of the object that is incited by virtue of the political work undertaken within ARC, and given the seemingly fluid re-contextualization of political activity within grassroots organizations, how do grassroots organizers maintain composure and strategic, political coherence when planning and designing? In other words, how do they struggle to collectively design political campaigns given the internally contradictory nature of organizations and their political activity? I argue that there is a narrative character to campaign design within ARE, typical perhaps of other grassroots organizations that elicit the following three qualities; 
(a) being practical, (b) collectivizing at all moments, and (c) preparing ourselves politically. By narrative character I mean robust design principles that account for contradictions, principles that enable those in leadership positions (as well as general members) to link different components and processes. These design principles serve as narratives or organizational stories or explanations for moving forward and collectivizing ideas and campaigns.

"We have to be practical." This statement, articulated by some of the members in the organization and discussed in a prior state wide leadership retreat, encapsulates the recognition that ARE organic structures are less layered and rigid when compared to institutions that are highly bureaucratic: its participants historically re-shape organic structures in fundamental ways. While participatory structures have been created within the organization, these guidelines function as tools (rather than strict rules) that guide action. Being practical in designing campaigns and undertaking research integral to its design reflects the ways in which organizing environments are conceived, i.e., as complex, changing, and contradictory. This ethos towards the practical should not be confused with crude pragmatism, although being practical often gets taken up in organizing spaces as a metaphor for activism without deliberate reflection. What this ethos represents is the shifting nature of organizing praxis. Campaigns begin yet suddenly cease; sometimes emerging spontaneously, at other times growing out of calculated collective action. For instance, the learning that unfolded in the design of the action-research on corporate charter schools became a resource for future praxis for the organization as a whole, beyond the ARC committee. In these instances, ARE members become the primary carriers of this renewed culture, with the knowledge generated forming an ever-expanding toolkit of organizing resources.

The problem of scaling up identified by learning scientists is reframed within a 
community organizing context as a problem of reinvention, where repetitions of practices in other spaces embody developmentally new activity. Scaling, as design researchers have conceptualized, tends towards viewing design along a horizontal plane: How can particular learning tools that work for a given setting be abstracted to other settings, say from one classroom to an entire school district? Although this way of seeing change within ARE is not at odds with the idea of reinventing practices, as a member of ARC and also privy to spaces that deliberately reflected upon building the organization as a whole, which materialized in the statewide Concilio, I have come to understand the problem of scaling in ARE-LA as manifest in the problem of cultural change. The production of the ARE Campaign Protocol, for example, represents an achievement within the organization. This protocol grew out of local struggles in ARC and other committees to define campaign processes. While not within this study, tracing the development of the Campaign Protocol highlights other contradictions. The protocol was not just about being pro-active with campaigns; it sought to address the reactionary politics of the ARE-LA chapter, a situation that the state wide Concilio had formally identified as a major cause of internal crises amongst members. Eventually ratified at the statewide leadership retreat, its design was meant to facilitate cross chapter campaign efforts during the following years, yet we learned that cultural change needed to be paralleled by the formation of our members and their own personal development. We could not just create new policies; they had to be appropriated in intimate ways by our membership.

"We have to collectivize at all moments." This statement, which became a motto of the organization as a whole and defined as a core value of the organization, expresses the undertaking to democratize and collectivize, specifically challenging individualistic models of decision-making and organizing. Decision-making emerges through consensus, which is quite 
challenging, involving extensive deliberation and tension. What this means for design within grassroots organizations like ARE is that it is seemingly slow because of the layering of practices and long term vision within the chapter to develop sustainable grassroots structures. Nonetheless this rhythm is not to be confused with the bureaucratization that characterizes institutional decision-making. Design within the campaign took a seeming tangent, as ARC members undertook action-research on what committee members came to frame as a deliberate corporate takeover of public schools. This research in turn mediated the expansion of the object, i.e., the political formation of teachers as community organizers (Figure 2, Object C). Yet, what is happened in ARC was mediated by other organic structures within the organization, such as the Mesa (i.e., leadership body) and General Body (i.e., membership). Democratic processes are both centralized and diffuse, and design is co-constructed via distinct, yet interacting, spaces. Moreover, a rational conception of the object is not necessary to carry forward campaign design; human aspects, such as trust that come with collectivization processes among members of an emergent community like ARE, enable the work to move forward.

"We have to become politically mature." A core value of ARE, manifest in other grassroots organizations (see Mann, 2011), was making the political development of the self the object. Because this is a core value, it is no coincidence that campaign design mediates political education. Design does not occur in a cultural vacuum—it is situated, cultural activity. The image of people brainstorming and behaving in a think-tank fashion at the planning table, testing new educational technologies and models, may be a caricature that obfuscates how planning and design are culturally specific processes, where identities, power, and discourse are a part of and therefore integral to rather than separate from design activity. These are integral components and 
not variables that need to be controlled. In grassroots organizing, all planning is deliberately political — infused by the value system, vision of possible worlds, etc. within the organization.

As the campaign to save South LA Elementary came to a standstill, what emerged within the campaign was consequential to this and also an opportunity the Mesa leadership envisioned: the possibility in building from the 8-month research as resources for continued political education for its members. The last Mesa meeting where we discussed terminating the campaign, led to a general agreement that the campaign could continue as a "case study of charter schools and community organizing" as Maria, chair of the chapter, suggested. This case study marked, I argue, a shift in the object, abandoning the idea to organize around the Expanded School Based Model (Figure 2, Object B) to developing ourselves politically as ARE members (Figure 2, Object C). What ensued were two concrete outcomes: the next issue of our journal Regeneración was dedicated to the theme "Neoliberal Privatization of Public Education" and presentations on the issue of neoliberal privatization at our annual statewide conferences. Moreover, several of our statewide Concilio members presented some of the ARC findings in a coalition space, Teacher Activist Groups, which had taken on the issue of standardization and privatization of urban schools. Elisa, then chair of the ARC committee, reflects on her own development as an organizer after our work in ARC:

People need to have a solid understanding of what the problem is, what we're trying to change, and everyone needs to be on the same page. You know we all need to be educated before we go out and protest or you know do anything like that, we all need to know.

She then reflects on her own development, seeing herself as an "organizer" in the local community surrounding South LA Elementary. This inclination to see campaigns with a vision 
toward sustainability and doing local work in the community marks a shift from activism to organizing. Hence, the object is not learning per se, an object presupposed by learning scientists, but the production of people, expressed as the political formation of ARE members (Figure 2, Object C). Thus, making the political formation of its members the object, testing of models may not be a central component to campaign development. Nonetheless, there is learning taking place that leads to the forging of expanded objects and the creation (and expansion) of practices, members, and the organization as a whole. The shift in a new expanded object is mediated largely by the integration of Mesa members in campaign discussions and also by the political development of ARE members both within the committee and in the general chapter.

\section{Toward Ethnographies of PDR: Implications for Theory and Methods}

Building upon the expansive learning cycle framework (Engeström, 2011), campaign design models in ARE are not necessarily tested in ways documented by learning scientists. Interestingly, expansive learning cycle processes may be manifest in the very development of a model. The efforts of ARE members to undertake a campaign that was eventually stalled, and their struggle to educate members, can be characterized as an 8-month process in re-envisioning and developing a model for taking collective action (via grassroots campaigns). Testing models when engaged in political work are high-risk activities, hence why organizers attempt to think carefully about political work. Yet, and this is important, they are pressed to react to situations of injustice. Ironically, public school reforms come and go and are mandated in top down fashion, with little input from those directly impacted by these policies. This is ironic in the sense that education is about real lives and people and schools, as much as they are historically layered bureaucracies, and should not be conceptualized as quasi-fixed laboratories for human intervention. 
PDR opens questions not just about the democratization of knowledge but how the inclusion of participants shape design practices and how these in turn are shaped by the spaces that make design possible. What is needed in order to understand the value of PDR are ethnographies of design activity that will assist learning scientists in reflecting upon the limits and possibilities of how they come about design, what voices are included and excluded, and how the entire research process is shaped, including the questions that orient the research all the way to its outcomes. A major lesson from campaign design within ARE-LA is that communities will likely have different priorities than those defined by learning scientists and will have developed their own endogenous strategies and ways of transforming practices via design that is organic to the space and community. Thus, making design activity visible within alternative and understudied sites such as grassroots spaces is an important step forward for expanding the emergent body of work on PDR. Nevertheless, making visible design practices should be oriented toward particular goals. The idea that design within ARE-LA centers the formation of its members is a lesson that points us in new directions, not to control and scale up innovations, but to center power, values and humanizing relations in studying and designing innovations that are fundamentally about human development.

While a science of design and theory of learning are certainly useful as ARE members develop the organization and refine artifact-practices (such as campaign development), a PDR framework presents an opening for rethinking design and learning as processes: design looks less like the way it is characterized by scholars and researchers in the learning sciences. An emergent, grounded theory of design (e.g., being practical, collectivizing at all moments, we have to become politically mature) enables us to understand how the mental models participants introduce are transformed in the process of engaging in concrete practical design activity. Within 
the development of the Save South LA Elementary campaign, action-research becomes integral to the expansion of the object and thus the formation of a new broader vision (i.e., conceptualization). There is no science or body of work that we drew upon to create a blueprint (i.e., the ideational aspect of design); the very work in the committee was an 8-month process where members educated themselves. This is perhaps a distinction with design research where experts who are not integral to the activity systems presume a science of learning. While not undervaluing the knowledge generated by design based learning scientists, what design looks like and who undertakes it (and for what purpose) desettles (Bang et al., 2012) design altogether - it is not just rational, scientific but is integral to the life of community, here the grassroots space of ARE. Research as part of the campaign design was thoroughly political and mediated a particular kind of anticipatory politics, an imagination of a different, possible world that centered the subject, members of the organization. Most ARE teachers, via action-research and political education, have come to understand their teaching as a struggle, a fight, against the corporate takeover of public education. As well, the struggle is defined broadly, where historically marginalized communities determine for themselves what education and liberation mean and how they will go about getting there.

Ethnographies of design activity can become useful reflexive tools for rethinking fundamental assumptions about learning and development. They are opportunities for testing learning theories "in the wild" via the inclusion of marginal spaces, people, and practices, and making assumptions about learning theories transparent. The situated nature of design that I outline in this study highlights fundamental assumptions about learning contexts, which I believe are congruent with principles found in cultural historical activity theory. 
- Learning theories should account for the situated and historically shaped nature of design;

- Learning theories should positioning design as integral to the study of learning and development and how design is itself a learning process;

- The relation between learning and development is a dialectical relation, where each transforms the others; yet real people engaged in practical work, including researchers, work collectively to transform their world-objects.

With respect to research of learning processes, this study of PDR brings to light several tensions, which I frame as productive rather than restrictive. First, because power is integral to all situated practices, the investigation of learning should re-center questions of equity by making visible what cognitivist and other learning theories tend to render invisible. Second, the investigation of the mediation of learning processes within alternative and marginal spaces (such as grassroots organizations) can help us understand sustained practices for equity and social justice-even in places, such as public schools, that work against equity and social justice. Third, by democratizing design, the focus on re-humanizing dynamics (however contradictory) shifts and potentially expands how culture and learning are investigated. When take together, these three tensions point to the possibility of PDR and a new wave of research rooted in rehumanizing praxis.

\section{References}

Akkerman, S. F., \& Bakker, A. (2011). Boundary crossing and boundary objects. Review of Educational Research 81(2), 132-169.

Anderson, L. (2006). Analytic autoethnography. Journal of Contemporary Ethnography, 35(4), 
$373-395$.

Bang, M., Medin, D., Washinawatok, K., \& Chapman, S. (2010). Innovations in culturally-based science education through partnerships and community. In M. Khine \& I. Saleh (Eds.) New science of learning: Cognition, computers and collaboration in education (pp. 569592). New York: Springer.

Bang, M., Warren, B., Rosebery, A. S., \& Medin, D. (2012). Desettling expectations in science education. Human Development, 55 (5-6), 302-318.

Barab, S. (2014). Design-based research: a methodological toolkit for engineering change. In R. K. Sawyer (Ed.), The Cambridge handbook of the learning sciences (pp. 151-170). New York: Cambridge University Press.

Blume, H. (2013, September 25). LAUSD halts home use of iPads for students after devices hacked. Los Angeles Times. Retrieved from http://www.latimes.com

Booker, A., Vossoughi, S., \& Hooper, P. (2014). Tensions and possibilities for political work in the learning sciences. In J. L. Polman, E. A. Kyza, D. K. O’Neill, I. Tabak, W. R. Penuel, A. S. Jurow, K. O’Connor, T. Lee, \& L. D’Amico (Eds.), Learning and becoming in practice: The International Conference of the Learning Sciences (ICLS) 2014, Volume 2 (pp. 919-926) Boulder, CO: International Society of the Learning Sciences.

Chang, H. (2008). Autoethnography as method. Walnut Creek, CA: Left Coast Press.

Cole, M. (2007). Sustaining model systems of educational activity: Designing for the long haul. In J. Campione, K., Metz, \& A. S. Palincsar (Eds.), Children's learning in laboratory and classroom contexts (pp. 71-87). New York: Routledge.

DiSalvo, C., Clement, A., \& Pipek, V. (2013). Communities: Participatory design for, with and by communities. In J. Simonsen \& T. Robertson (Eds.), Routledge international 
handbook of participatory design (pp. 182-210). New York: Routledge.

DiSalvo, B., \& DiSalvo, C. (2014). Designing for democracy in education: Participatory design and the learning sciences. In J. L. Polman, E. A. Kyza, D. K. O’Neill, I. Tabak, W. R. Penuel, A. S. Jurow, K. O’Connor, T. Lee, \& L. D’Amico (Eds.), Learning and becoming in practice: The International Conference of the Learning Sciences (ICLS) 2014, Volume 2 (pp. 793-799) Boulder, CO: International Society of the Learning Sciences.

Engeström, Y. (2009). From learning environments and implementation to activity systems and expansive learning. Actio: An International Journal of Human Activity Theory 2, 17-33.

Engeström, Y. (2011). From design experiments to formative interventions. Theory \& Psychology 21(5), 598-628.

Engeström, Y., \& Sannino, A. (2010). Studies of expansive learning: foundations, findings, and future challenges. Educational Research Review 5, 1-24.

Fals-Borda, O. (1970). Ciencia propia y colonialism intelectual. Mexico, D. F.: Editorial Nuestro Tiempo.

Fals-Borda, O. (2006). The north-south convergence: A 30 year first person assessment of PAR. Action Research, 4(3), 351-358.

Gutierréz, K., \& Vossoughi, S. (2010). Lifting off the ground to return anew: Mediated praxis, transformative learning, and social design experiments. Journal of Teacher Education $61(1-2), 100-117$.

Lee, C. D. (2013). Conceptualizing cultural and racialized process in learning. Human Development, 55 (5-6), 348-355.

Mann, E. (2011). Playbook for progressives: 16 qualities of the successful organizer. Baston, MA: Beacon Press. 
Medin, D. L., \& Bang, M. (2014). Who's asking? Native science, western science, and science education. Cambridge, MA: MIT Press.

Moran, T. P., \& Carroll, J. M. (1996). Overview of design rationale. In T. P. Moran \& J. M. Carroll (Eds.), Design rationale: Concepts, techniques, and use (pp. 1-20). Mahwah, NJ: Lawrence Erlbaum.

Nasir, N. S., Roseberry, A. S., Warren, B., \& Lee, C. D. (2014). Learning as a cultural process: Achieving equity through diversity. In R. K. Sawyer (Ed.), The Cambridge handbook of the learning sciences (pp. 686-706). New York: Cambridge University Press.

Penuel, W. R., Fishman, B. J., Cheng, B. H., \& Sabelli, N. (2011). Organizing research and development at the intersection of learning, implementation, and design. Educational Researcher, 40(7), 331-337.

Penuel, W. R. (2014). Emerging forms of formative intervention research in education. Mind, Culture, and Activity 21(2), 97-117.

Razzouk, R., \& Shute, V. (2012). What is design thinking and why is it important? Review of Educational Research 82(3), 330-348.

Svihla, V. (2014). Advances in design-based research. Frontline learning research, 2(4), 35 45. 


\section{Endnotes}

${ }^{1}$ Passed in 2009 by the Los Angeles Unified School District (LAUSD) School Board, Public School Choice: A New Way at LAUSD allows for internal and external organizations to create more schools of choice, replacing existing low performing schools. By 2009, there were several charter management organizations (CMOs) in the district. By definition, CMOs are corporations. Green Dot, for example, hires teachers on yearly contracts, screens prospective students, and is run with a business-type of ideology. While not all CMOs have the same policies and not all "choice" options include CMO appropriation, the core concern for many teachers I came across in my organizing through ARE is that low performing public schools, rather than being funded at adequate levels, would be taken over by a CMO. For the policy text of the motion, go to:

http://laschoolboard.org/sites/default/files/PublicSchoolChoice.pdf. 
Figure 1. Situating the ARC Committee within ARE organic structures.

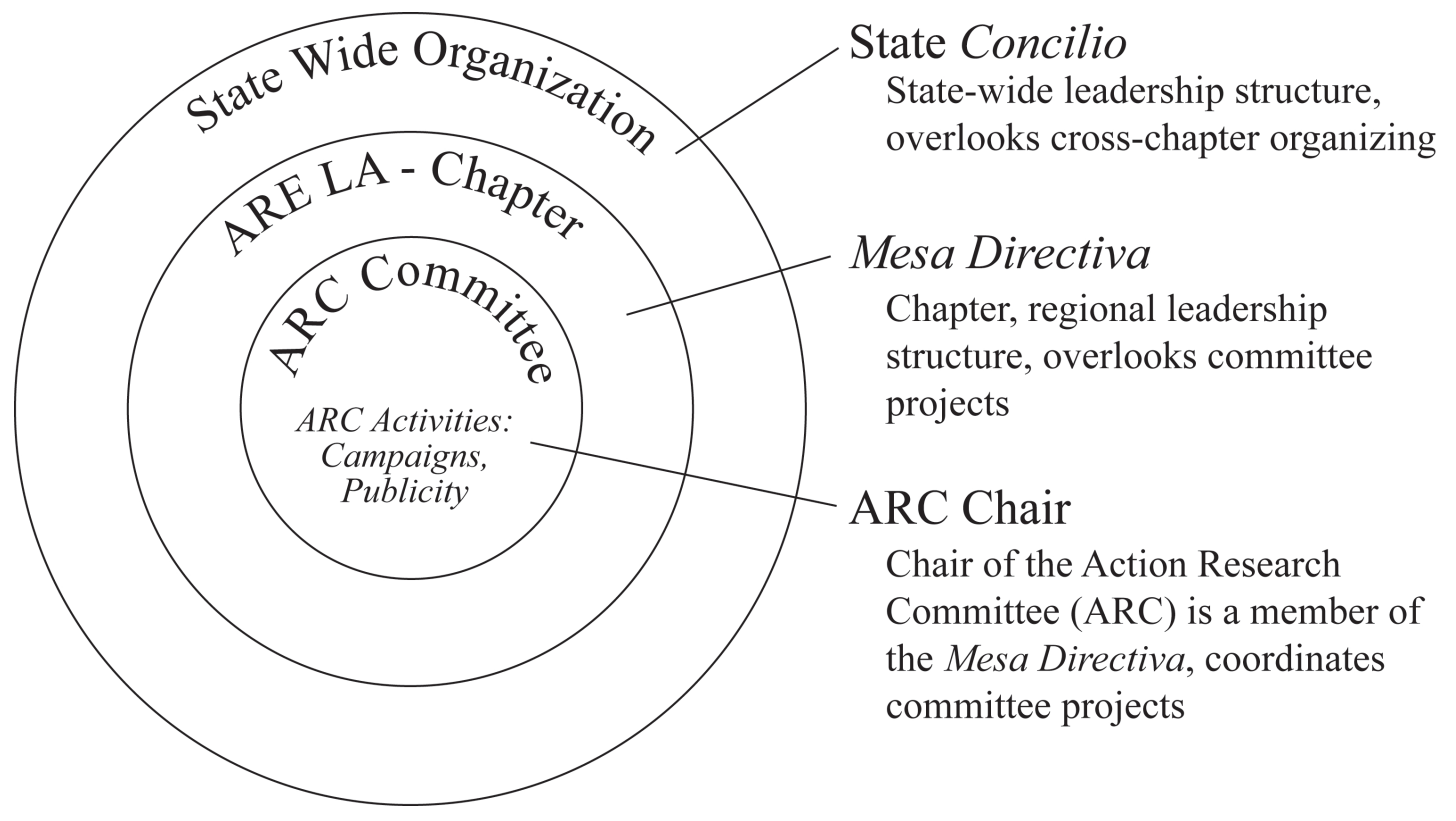


Figure 2. Activity system model of the Save South LA Elementary campaign.

TOOLS

Campaign Design - Protocol

Action-Research Design

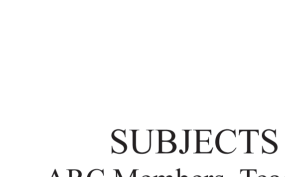

ARC Members, Teachers in South LA Elementary
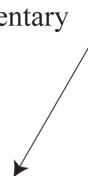

$$
4
$$
Committee Structures Chapter Structures

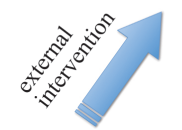

District Policy: Public School Choice

Chapter General Body

State-Wide Organization
Action Research

Committee (ARC)

Chapter Mesa

\section{OBJECT}

A: Non-Charterization

of South LA Elementary $\quad$ C: Political Formation

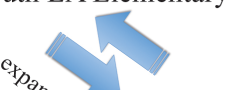

B: Expanded School

Based Model

DIVISION OF LABOR

ARC Committee Members

Collaborative, Consensus

Chapter Mesa

Chapter General Body of ARE teachers: from "activists" to "organizers" 